\title{
Poemas Antología 2015
}

\section{Poetry Antology 2015}

\begin{abstract}
Antonio Acevedo Linares
Poeta, Ensayista y Sociólogo

Universidad Autónoma de Bucaramanga

Magíster en Filosofía Latinoamericana - énfasis en Educación y Filosofía Colombiana Universidad Santo Tomás

Especialista en Filosofía Política Contemporánea Universidad de Antioquia antonioacevedolinares@msn.com

Recibido el 10 de febrero del 2015

Aprobado el 04 de mayo del 2015
\end{abstract}

\section{Las musas}

Los númenes que

inspiran a los poetas

protectora de las ciencias

y las artes

según la fábula

nueve deidades que

habitaban en el Helicón

o Parnaso

con una tablilla

y una pluma, Calíope

guerrera musa de la poesía épica

con un rollo de papiro 
y un libro en la mano, Clío

intelectual musa de la historia

con una lira, Erato

sensual musa de la poesía erótica

con una flauta, Euterpe

sentimental musa de la poesía lírica

con una máscara trágica, Melpómene

dramática musa de la tragedia

con una máscara cómica, Talía

risueña musa de la comedia

en una actitud meditativa, Polimnia

mística musa de la canción sacra

con una lira, Terpsícone

hermosa musa de la canción y la danza

con un puntero señalando

un globo, Urania

espacial musa de la astronomía.

Las invoco bajo este

cielo enlunado

para que canten

los poetas de la tierra. 


\section{Epigrama}

Los hombres lo escalan

con verdadera proeza

en la cordillera del

Himalaya el monte Everest

en el Pico de los Andes

el monte Aconcagua

en Taganyka en el África

oriental el monte Kilimanjaro.

En tu cuerpo yo apenas

escalo el monte de Venus.

\section{El Rojo}

Alejandra y yo

éramos jóvenes

y teníamos un sueño

queríamos cambiar el mundo

pero el mundo terminó

por hacernos cambiar a nosotros

y el color de los uniformes

de campaña, los brazaletes de insignias

alrededor del brazo y la boina

bajo una melena al viento

nos hacía sentir que éramos los elegidos

los que íbamos a cambiar el mundo

junto a otros hombres y mujeres

que como nosotros tenían un sueño

y cuando con nostalgia recuerdo

a ese argentino con rostro de nazareno

crucificado y creo que teníamos 
toda la ternura y el coraje para

que no se convirtieran en

escombros los sueños

que teníamos de cambiar

el mundo que odiábamos.

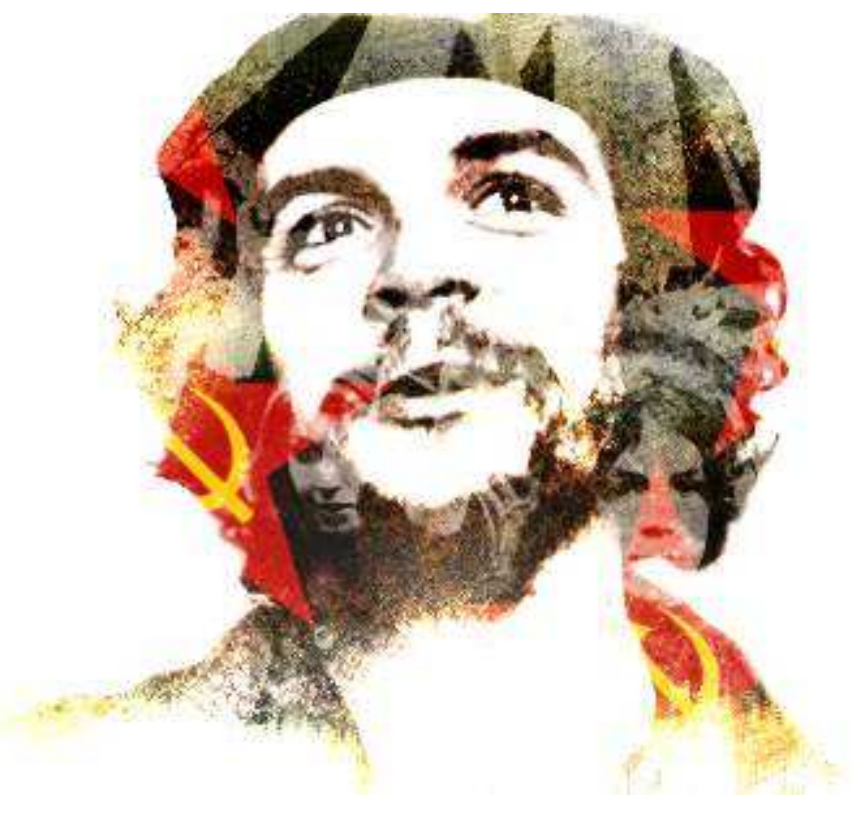

\section{Antimadrigal}

Los poetas fueron

expulsados de la República

Adán y Eva fueron

arrojados del Paraíso

y el Ángel fue arrojado del cielo

y convertido en Demonio.

Arrojado de tu cuerpo

el paraíso que no quisiste

que tuviéramos en la tierra

me convierto en el poeta que canta

la memoria del día que fui arrojado

del paraíso y el cielo de tu cuerpo. 


\section{Canción I}

La música del flautista de Hamelin

Los girasoles de Van Gogh

La sonrisa de la Gioconda

El barco ebrio de Rimbaud

Las estaciones e Vivaldi

Los ditirambos de Catulo

Las golondrinas de Bécquer

La isla de Robinson Crusoe

La poética de Aristóteles

La ceguera de Homero

La luna en el río que vio Li Po

El hilo infinito de Penélope

El hilo infinito de Ariadna

La constelación de Orión

La paloma blanca de Picasso

El teorema de Pitágoras

El sueño de Chuang Tzu

El río de Heráclito

La desnudez de la Maja

La locura de Artaud

Los diálogos de Platón

Las fábulas de Esopo

La lira de Orfeo

La rosa de Rilke

Sean tus ojos como la pródiga

eternidad de esas infinitas cosas. 


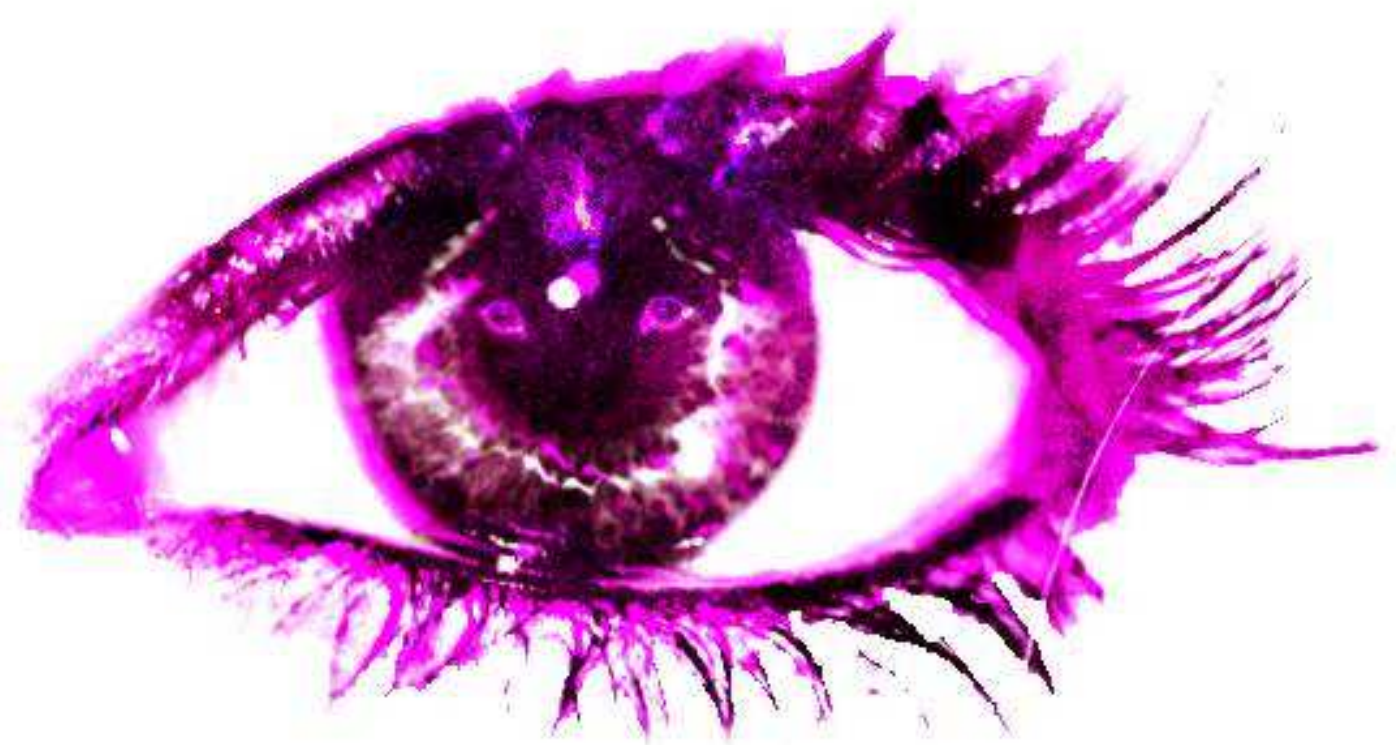

\section{Canción II}

Quiero erigir a

la memoria esa tarde

en que Sócrates

bebió la cicuta

paseándose entre los muros

de la cárcel

el olor de la rosa

que respiró Van Gogh

mientras la dibujaba

como una carta a Theo

las cenizas de Juana de Arco

en la hoguera en

la plaza de Ruán

ese hermoso prodigio

de Confucio que no termino

de celebrar: sé como

el sándalo que perfuma

el hacha que lo corta

la mano que dibujó

un bisonte en 
la cueva de Altamira

herido por la flecha

el río de Heráclito

que fluye eterno

como el tiempo

esa noche en que el Quijote

sueña a Cervantes

que lo escribe

en una celda en Argel

para que tus ojos

me recuerden

como esas antiguas cosas

que la memoria erige. 